15

\title{
Применение нанопорошков окиси церия для полировки кремния
}

\author{
() Н.И. Чхало, ${ }^{1}$ А.А. Ахсахалян, ${ }^{1}$ Ю.А. Вайнер, ${ }^{1}$ М.В. Зорина, ${ }^{1}$ А.Е. Пестов, ${ }^{1}$ М.В. Свечников, ${ }^{1}$ \\ M.H. Торопов, ${ }^{1}$ N. Kumar, ${ }^{1}$ Ю.М. Токунов ${ }^{2}$ \\ ${ }^{1}$ Институт фризики микроструктур РАН, \\ 607680 Нижний Новгород, Россия \\ ${ }^{2}$ МФТИ, \\ 141701 Долгопрудный, Московская обл., Россия \\ e-mail: chkhalo@ipm.sci-nnov.ru
}

Поступило в Редакцию 2 апреля 2021 г.

В окончательной редакции 2 апреля 2021 г.

Принято к публикации 2 апреля 2021 г.

Описаны методы исследований и первые результаты, полученные при изучении шероховатости подложек из монокристаллического кремния (111), обработанных на финальной стадии различными способами: традиционная полировка без использования химико-механической полировки (ХМП), с использованием ХМП и без ХМП, но с применением нанопорошков окиси церия. Продемонстрирована эффективность использования нанопорошков $\mathrm{CeO}_{2}$. Были получены следующие значения эффективной шероховатости: без ХМП $-3.56 \mathrm{~nm}$, с ХМП $-0.54 \mathrm{~nm}$ и без ХМП, но с полировкой $\mathrm{CeO}_{2}-0.93 \mathrm{~nm}$.

Ключевые слова: поверхность, шероховатость, рентгеновская оптика, глубокая шлифовка-полировка.

DOI: $10.21883 /$ JTF.2021.10.51375.95-21

\section{Введение}

В последнее время в связи с модернизаций синхротронов 3-го поколения и появлением лазеров на свободных электронах и синхротронов 4-го поколения, в том числе активно разрабатываемого в нашей стране СКИФ (Сибирский кольцевой источник фотонов) [1] стала еще более актуальной проблема радиационной стойкости зеркал. Для этих приложений есть еще дополнительное условие, связанное с необходимостью сохранения когерентных свойств исходного пучка. Поэтому на первый план выходят термоиндуцированные искажения формы зеркал. Для оценки допустимых искажений формы можно воспользоваться следующими рассуждениями. Для обеспечения дифракционного качества изображений необходимо, чтобы при отражении в каждой локальной точке падения фаза отраженного пучка не изменялась более чем на четверть длины волны. С учетом скользящего падения излучения на зеркало это условие можно переписать в виде

$$
\Delta X<\lambda / 4(\sin \theta)^{-1},
$$

где $\Delta X-$ локальное отклонение профиля зеркала от расчетного, $\lambda$ - длина волны и $\theta-$ скользящий угол падения. Для зеркал с многослойными покрытиями, увеличивающими рабочие углы зеркал в несколько раз [2-4], с учетом условия Брэгга соотношение (1) можно переписать в виде

$$
\Delta X<D / 2
$$

где $D$ - период многослойного зеркала. Для характерных периодов, часто используемых W/B4C многослойных зеркал $D=2 \mathrm{~nm}$ [5]. Допустимая ошибка лежит в субнанометровой области.
Для сохранения высоких коэффициентов отражения микрошероховатость подложек должна быть меньше, чем межслоевая шероховатость в многослойных зеркалах, которая в случае W/B4C составляет около $0.2 \mathrm{~nm}[6]$.

Как показали теоретические расчеты, которые полностью подтвердились на практике, для минимизации термоиндуцированных искажений формы в качестве материала подложек можно использовать только монокристаллический кремний. Другие материалы, в том числе карбид кремния и металлы (медь, алюминий, бериллий) по своим теплофизическим характеристикам сильно ему уступают $[7,8]$.

В настоящее время наиболее распространенным методом получения высокоточных, в том числе кремниевых асферических подложек для зеркал является комбинация алмазного точения и коррекции локальных ошибок формы малоразмерными ионными пучками [9-12]. В качестве альтернативы алмазному точению используется полировка малоразмерными полировальниками с компьютерным контролем [13]. Однако при такой обработке развиваются шероховатости в диапазоне пространственных частот $10^{-3}-1 \mu \mathrm{m}^{-1}$, называемые среднечастотными и обусловленные биениями инструмента, которые в наибольшей степени влияют на разрешающую способность рентгенооптических систем [14]. Поэтому лучшие результаты по точности изготовления кремниевых подложек были достигнуты с использованием технологии, называемой авторами Computer-controlled elastic emission machining [15]. Эта технология в качестве полирующего инструмента использует локализованную струю суспензии, подаваемую под давлением 100 атмосфер. Помимо высокой степени контролируемости процесса обработки, из-за отсутствия нормальной составляющей давления 
на абразивные зерна в суспензии, всегда имеющей место при традиционной шлифовке-полировке, при таком способе не возникает нарушенный слой, связанный с растрескиванием приповерхностных областей подложки. Японская корпорация JTEC CORPORATION, освоившая эту технологию, является фактически монополистом по изготовлению высокоточных кремниевых подложек для синхротронных применений [16].

В последние годы для получения высокоточных подложек для зеркал дифракционного качества в рентгеновском диапазоне мы развиваем двухстадийный подход. Общеизвестно, что при шлифовке-полировке плоских и сферических поверхностей благодаря взаимному притиру достигается наилучшее качество обработки оптических поверхностей [17]. Поэтому на первой стадии методом притира изготавливаются сферические (плоские) подложки с радиусом кривизны, наиболее близким к требуемой асферике. На второй стадии с использованием специально разработанной установки ионно-пучкового травления [18] проводится коррекция локальных ошибок и асферизация формы.

Высокая контролируемость процесса ионно-пучковой обработки позволяет создавать высокоточные, с очень сложной формой асферики, поверхности, и, как следствие, разрабатывать уникальные оптические схемы, которые ранее не удавалось реализовать $[19,20]$. Однако для успешной реализации этого подхода необходимо на первом этапе получить подложки с высокой гладкостью поверхности, так как ионные пучки хорошо сглаживают высокочастотные шероховатости и практически не влияют на среднечастотные, начиная с частот $0.2-0.3 \mu \mathrm{m}^{-1}[21,22]$. В [23] на подложках из плавленого кварца были изучены суспензии с микропорошками из $\mathrm{CeO}_{2}$. Эти порошки продемонстрировали свою высокую эффективность. На довольно крутой сферической подложке диаметром $100 \mathrm{~mm}$ и радиусом кривизны $137.5 \mathrm{~mm}$, числовая апертура $\mathrm{NA}=0.36$ была получена эффективная шероховатость около $0.2 \mathrm{~nm} \mathrm{в}$ диапазоне частот $0.025-65 \mu \mathrm{m}^{-1}$. При этом была достигнута точность формы: максимальный перепад высот $\mathrm{MP}=16 \mathrm{~nm}$ и среднеквадратическое отклонение $\mathrm{CKO}=3.3 \mathrm{~nm}(\approx \lambda / 200)$. После ионной полировки эффективная шероховатость падала примерно до $0.1 \mathrm{~nm}$, что уже вполне достаточно для рентгеновской оптики дифракционного качества.

Целью настоящей работы было исследование возможности применения этой технологии и микропорошков для полировки монокристаллического кремния.

\section{1. Методика эксперимента}

\section{1. Методика механического притира}

Как и в [23], использовался доводочный станок Д-150. Обработка поверхности велась смоляным полировальником (марка смолы СП5). На начальной стадии притира использовалась та же суспензия на основе водяного

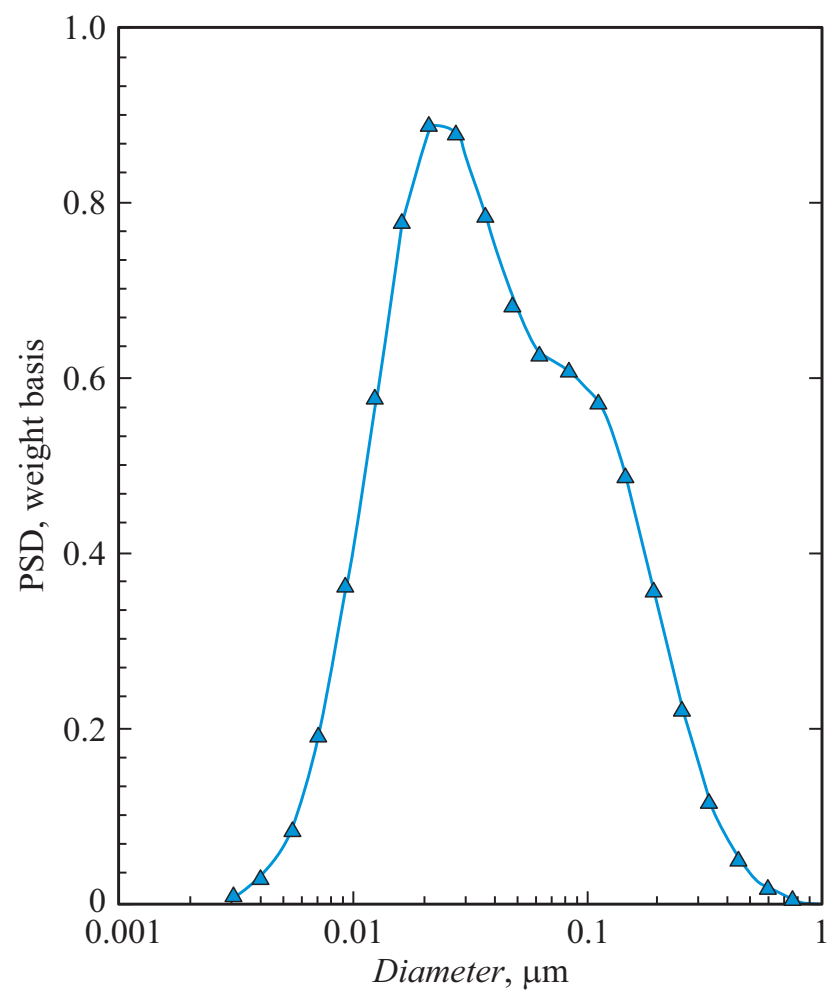

Рис. 1. Распределение порошка $\mathrm{CeO}_{2}$ по размерам в доработанной суспензии.

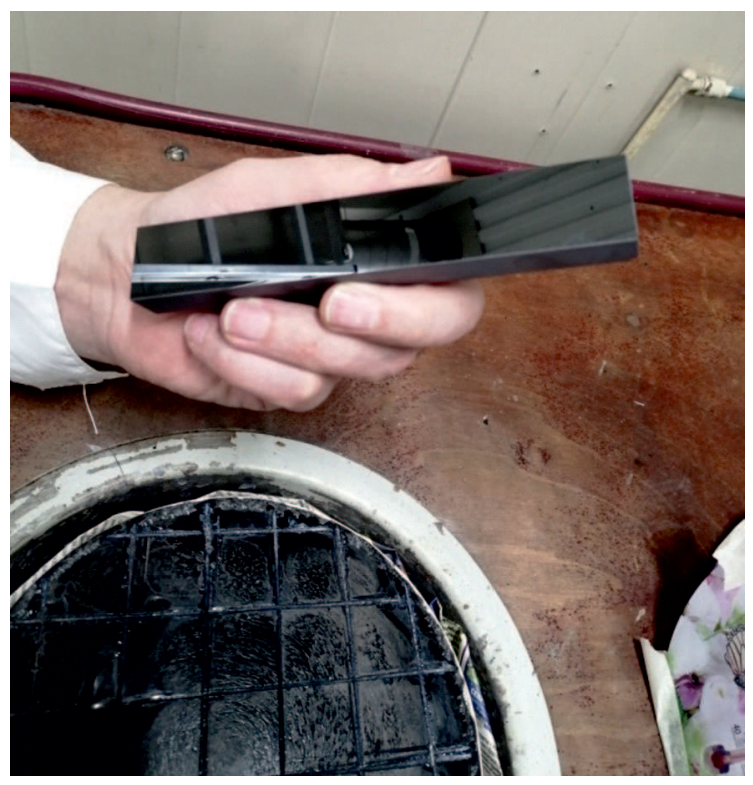

Pис. 2. Фотография обрабатываемой подложки.

раствора микропорошков оксида церия производства МФТИ, г. Долгопрудный, с размерами зерна $0.1-0.3$ и 0.05-0.1 $\mu \mathrm{m}$. На заключительной стадии использовалась суспензия, изготовленная по доработанному технологическому маршруту с добавлением фракции нанопорошка $\mathrm{CeO}_{2}$ с размером частиц $19 \mathrm{~nm}$. На рис. 1 приведено распределение частиц порошка по размерам. Как видно 
из рисунка, распределение имеет бимодальный характер с максимумами 22 и $108 \mathrm{~nm}$.

Обрабатываемая подложка, фотография которой приведена на рис. 2, представляла собой параллелепипед из монокристаллического кремния (111) с размерами $15 \times 25 \times 120 \mathrm{~mm}$. Кристаллографическая ориентация (111) выбрана с перспективой дальнейшего ионнопучкового травления для уменьшения высокочастотной шероховатости, так как поверхность $\mathrm{Si}$ (111) можно эффективно сгладить при травлении под нормалью.

\section{2. Методы измерений шероховатости}

Предметами исследований были статистические свойства шероховатости поверхности и глубина нарушенного слоя. Как уже отмечалось в ряде работ, например, [24], изучение шероховатости сверхгладких поверхностей имеет ряд особенностей, требующих критического подхода при анализе реальных возможностей используемых приборов и методов. В частности, широко используемый метод интерферометрии белого света $[25,26]$ удовлетворительно работает только для поверхностей с эффективной шероховатостью выше $1 \mathrm{~nm}$ [21]. На спектры диффузного рассеяния рентгеновского излучения (ДРРИ) [27,28] значительное влияние может оказать наличие нарушенного слоя, который приводит к дополнительному рассеянию на объемных неоднородностях [29]. Атомно-силовая микроскопия (АСМ) [30] страдает нелинейностью сканера, которая проявляется при больших, более $10 \mu \mathrm{m}$, кадрах [21]. На результаты измерений значительное влияние может оказать механическая жесткость балки кантилевера. Также при АСМ измерениях необходимо учитывать шумы, которые зависят не только от характеристик используемого прибора, но и внешних условий [31]. Поэтому мы признаем результаты измерений шероховатости достоверными, если функции спектральной плотности мощности шероховатостей PSD (power spectral density), измеренные различными методами, совпадают в области пересечения их рабочих диапазонов.

В настоящей работе применялись методы зеркального и диффузного рассеяния рентгеновского излучения и АСМ. Величина и угловое распределение ДРРИ определяются главным образом частотным спектром рассеивающего рельефа. Если выполняются условие малости шероховатости и угла скольжения

$$
k \sigma \sin \theta_{0} \ll 1 ; \quad k \sigma\left|\varepsilon_{+}-\cos \theta_{0}\right|^{1 / 2},
$$

где $k-$ волновое число, $\sigma-$ среднеквадратичная шероховатость, $\theta_{0}$ - угол скольжения зондирующего пучка, означающее, что поле волны мало меняется на масштабе $\pm \sigma$ от рассеивающей границы [27], то для интенсивности рассеяния, проинтегрированной по азимутальному углу, можно записать выражение

$$
\begin{aligned}
& \Pi\left(\theta, \theta_{0}\right)=\frac{k^{5}}{16 \pi k_{-}\left(q_{0}\right) \sqrt{q_{0} q}} \\
& \times\left|\int \psi_{0}\left(z, q_{0}\right) \psi_{0}(z, q) \varepsilon^{\prime}(z) d z\right|^{2} \operatorname{PSD}_{1 D}(p),
\end{aligned}
$$

где $\theta-$ угол рассеяния $q_{0}=k \cos \theta_{0}, q=k \cos \theta$, $\psi_{0}(z, q)$ - распределение поля в структуре, $\operatorname{PSD}_{1 D}(p)-$ одномерная спектральная плотность мощности рельефа, $p$ - пространственная частота.

В случае рассеяния на одной поверхности с резким скачком $\varepsilon$

$$
\Pi\left(\theta, \theta_{0}\right)=\frac{k^{3}|1-\varepsilon|^{2}}{16 \pi \sin \theta_{0}}\left|t\left(\theta_{0}\right) t(\theta)\right|^{2} \operatorname{PSD}_{1 D}(p),
$$

где $t(\theta)$ - френелевский коэффициент прохождения.

Важно, что независимо от структуры приповерхностного слоя интенсивность рассеяния состоит из двух множителей - электродинамического фактора - функции одномерной слоистой геометрии структуры, длины волны и геометрии эксперимента - и спектра шероховатостей. Если электродинамический фактор известен, то простым делением экспериментально измеренной интенсивности (с учетом инструментальной функции) на этот множитель получается искомый спектр

$$
\begin{aligned}
\operatorname{PSD}_{1 D}(p)= & \Pi_{\exp }\left(\theta, \theta_{0}\right) / \frac{k^{2}}{16 \pi k_{-}\left(q_{0}\right) \sqrt{q_{0} q}} \\
& \times\left.\int \psi_{0}\left(z, q_{0}\right) \psi_{0}(z, q) \varepsilon^{\prime}(z) d z\right|^{2} .
\end{aligned}
$$

Геометрия эксперимента известна априори, одномерная слоистая структура образца находится по результатам подгонки кривых отражения и диффузного рассеяния с использованием предварительной модельной PSD.

Эффективная шероховатость $\sigma_{\text {eff }}$ поверхности определяется из соотношения

$$
\sigma_{\mathrm{eff}}^{2}=\int_{p_{\min }}^{p_{\max }} \operatorname{PSD}_{1 D}(p) d p,
$$

где $p_{\min }$ и $p_{\max }$ - минимальная и максимальная пространственные частоты, в интервале между которыми находится PSD-функция.

\section{2. Экспериментальные результаты}

Первоначально в качестве „эталона“ для сравнения изучалась стандартная кремниевая пластина для микроэлектронной промышленности, прошедшая процедуру химико-механической полировки (ХМП). Известно, что таким способом получаются самые гладкие подложки с полностью убранным нарушенным слоем. Единственным недостатком этой технологии полировки кремния 

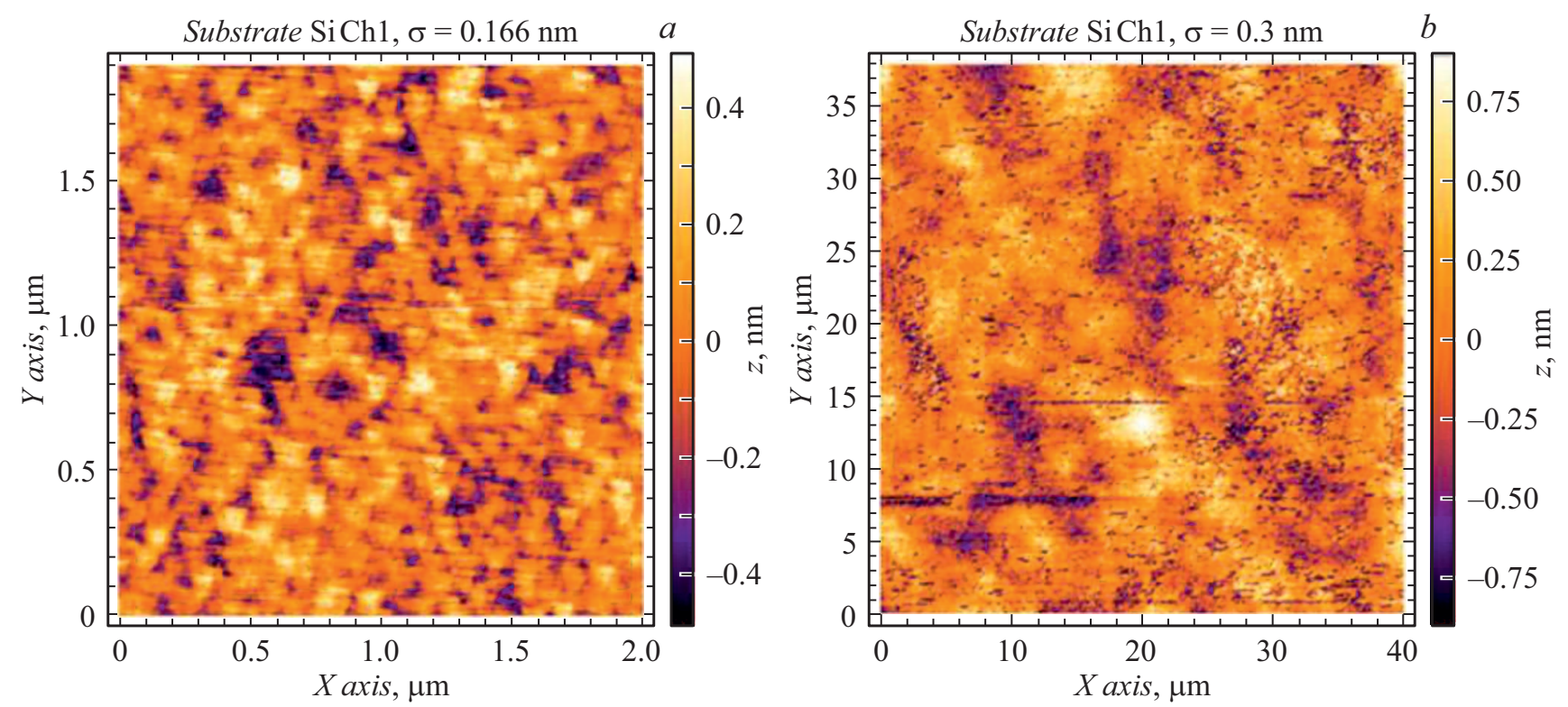

Рис. 3. АСМ изображения поверхности кремния для микроэлектронной промышленности после ХМП.

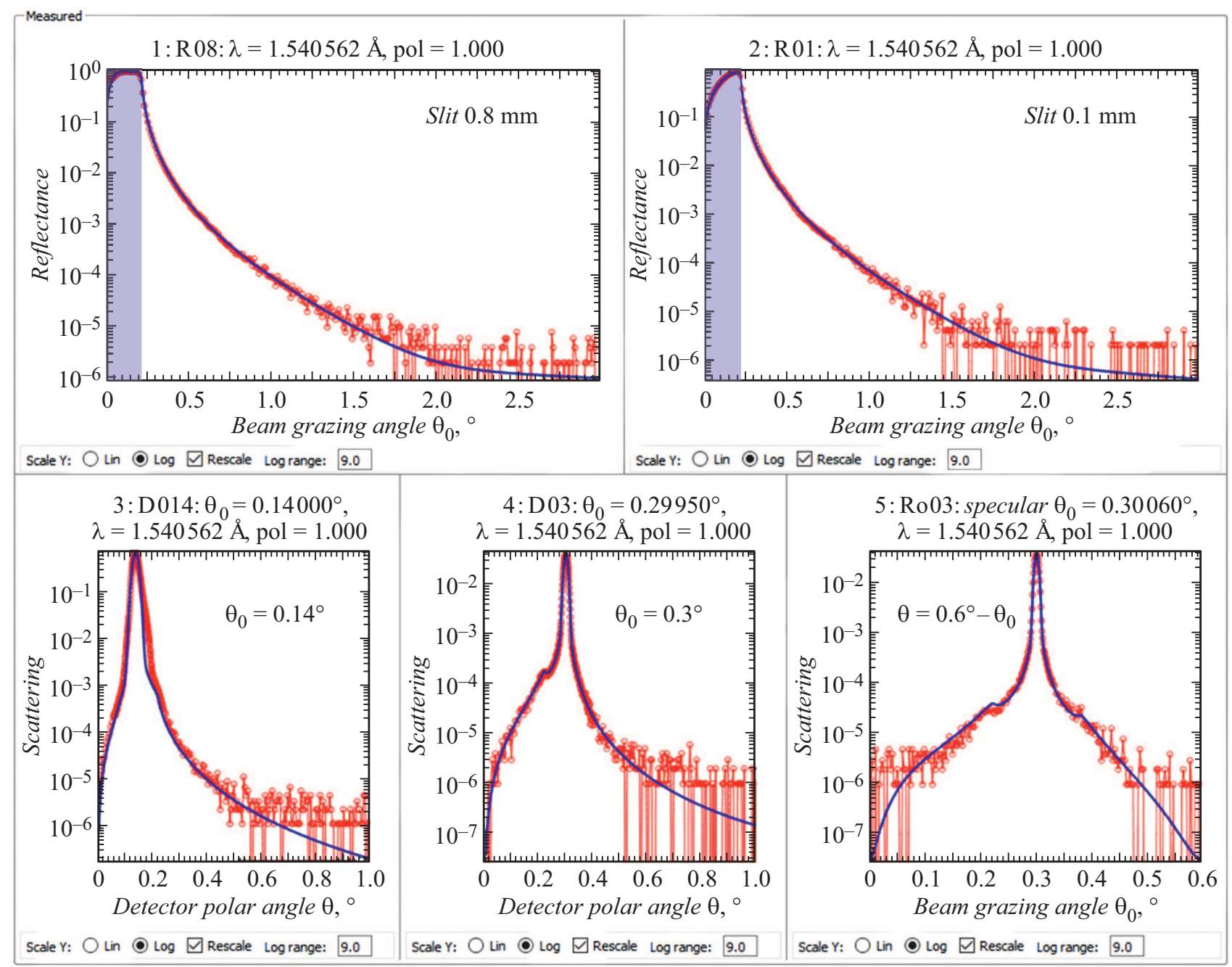

Рис. 4. Кривые зеркального отражения (сверху), измеренные с различными щелями на детекторе, диффузного рассеяния (внизу) для исследуемого образца. 


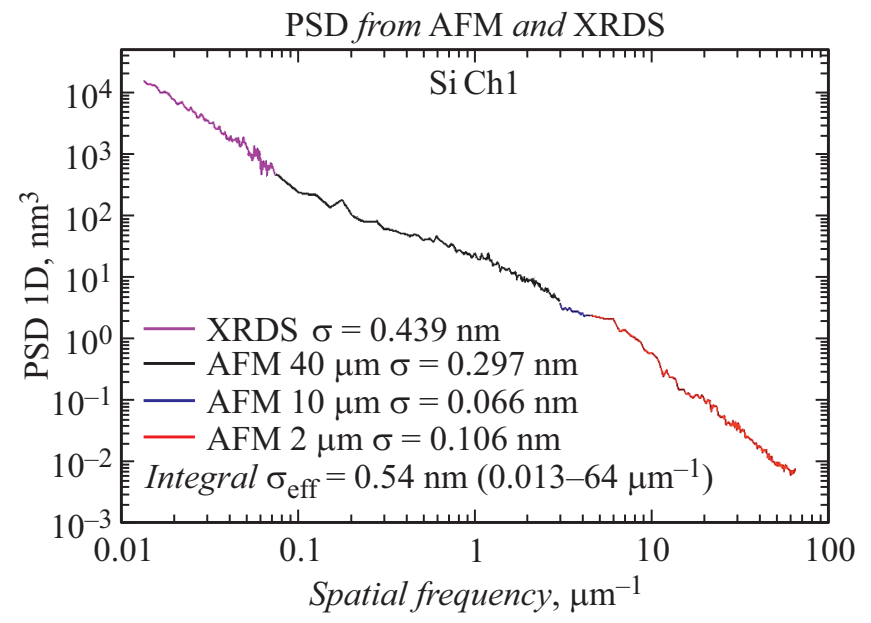

Рис. 5. PSD-функция шероховатости, построенная по данным АСМ и ДРРИ.

применительно к рентгенооптическим задачам является неудовлетворительная точность формы поверхности, связанная с использованием полировальников из „мягких“ материалов и сложностью ее контроля в процессе химического травления. Тем не менее, с точки зрения шероховатости и нарушенного слоя, это может считаться эталоном.

На рис. 3 и 4 приведены АСМ изображения и кривые зеркального отражения (рис. 4, сверху), и диффузного рассеяния (рис. 4 , внизу) для исследуемого образца.

Моделирования кривых рентгеновского отражения и рассеяния проводились с использованием программы Multifitting [32]. Видно, что кривые хорошо моделируются. Есть небольшое расхождение в области отраженного пучка при угле падения $0.14^{\circ}$. Однако причиной это- го расхождения является неизбежная при закреплении кривизна тонкой пластины, эффект которой растет с уменьшением угла.

По данным АСМ и ДРРИ была построена функция спектральной плотности мощности шероховатостей, приведенная на рис. 5. На рисунке помимо интегральной шероховатости указаны эффективные шероховатости как площади под соответствующими частями PSD-функции. Эти эффективные шероховатости не являются полными шероховатостями по соответствующему кадру, а соответствуют только части PSD, представленной на графике.

Эффективная шероховатость поверхности после ХМП в диапазоне частот $0.013-64 \mu \mathrm{m}^{-1}$ составила около $0.54 \mathrm{~nm}$. Следует отметить, что практически совпадающие значения были получены при изучении $\mathrm{Si}$ пластин после ХМП для микроэлектронной промышленности в [33]. Хорошая сшивка PSD-функций, полученных обоими методами, подтверждает, что рассеяние главным образом определяется поверхностью, а не нарушенным слоем.

Аналогичные измерения были проведены для экспериментального образца после стандартной глубокой шлифовки-полировки (ГШП). На стадии шлифовки применялись микропорошки карбида бора с размерами зерна $14 \mu \mathrm{m}$ в начале и $7 \mu \mathrm{m}$ в конце. После карбида бора тонкая шлифовка и полировка осуществлялись алмазными микропорошками с размером зерна, изменяющимся от $5 \mu \mathrm{m}$ до субмикрометра. Финальная полировка заканчивалась полиритом. Необходимо отметить, что процедура ГШП производилась на „твердых“ смоляных полировальниках с тем, чтобы обеспечивать надежный притир и высокое качество плоскостности детали. Результаты АСМ измерений приведены на рис. 6, рентгеновские - на рис. 7. Функция спектральной плотности
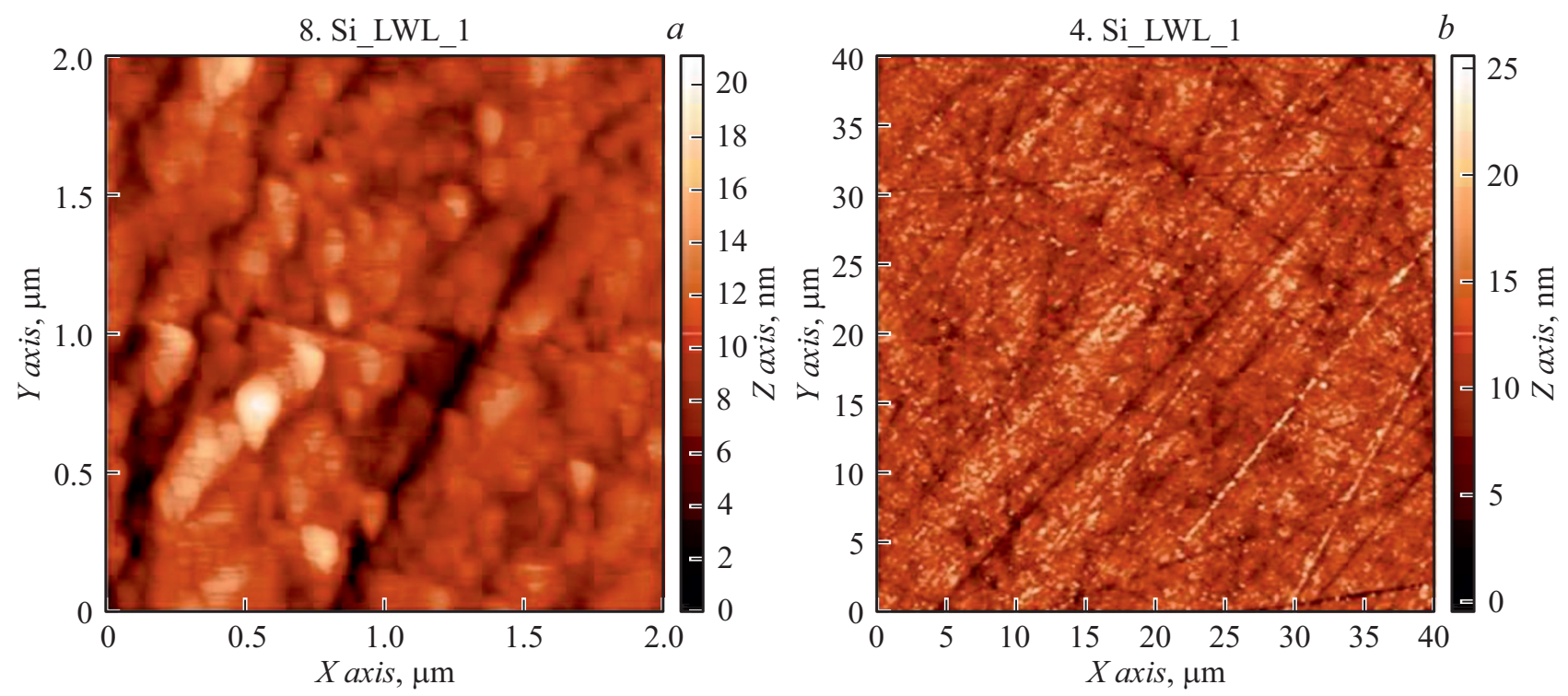

Рис. 6. АСМ изображения поверхности исследуемого образца после ГШП без ХМП. 


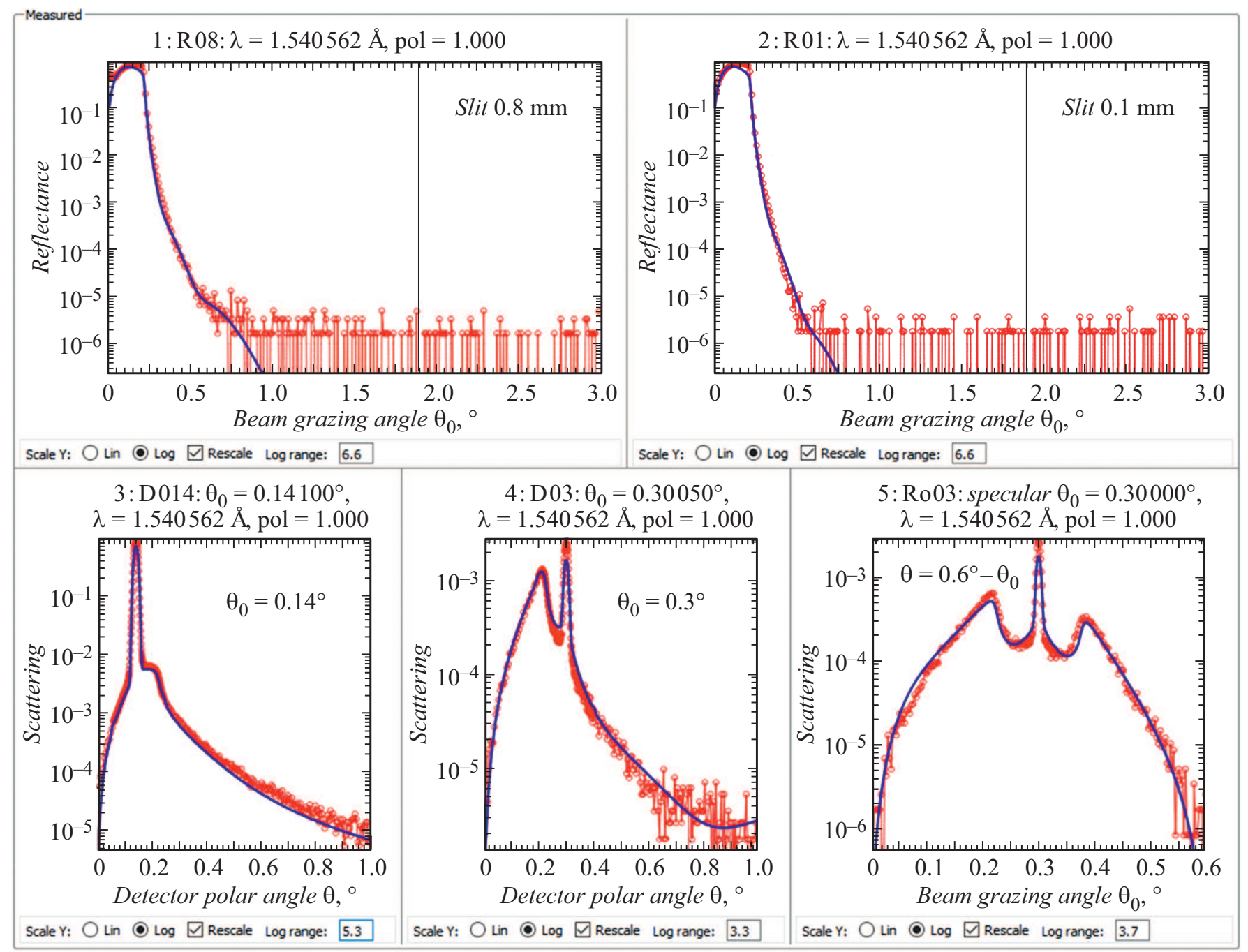

Рис. 7. Кривые зеркального отражения (сверху), измеренные с различными щелями на детекторе, диффузного рассеяния (внизу) для исследуемого образца после ГШП без ХМП.

мощности шероховатости, построенная по данным АСМ и ДРРИ, приведена на рис. 8.

Как видно из рисунков, эффективная шероховатость подложки кремния после ГШП, но без ХМП, сильно уступает подложкам после ХМП и не удовлетворяет требованиям для рентгеновских зеркал. Эффективная шероховатость в диапазоне частот $0.0073-64 \mu \mathrm{m}^{-1}$ составила $3.56 \mathrm{~nm}$.

После исследований была проведена процедура притира с использованием суспензий на основе нанопорошков оксида церия, описанных в начале настоящей работы. Притир также осуществлялся на смоляном полировальнике в течение $2 \mathrm{~h}$. Результаты измерений приведены на рис. 9-11.

Как следует из приведенных экспериментальных данных, применение на финальной стадии суспензии с $\mathrm{CeO}_{2}$ нанопорошками уменьшило шероховатость почти в 4 раза, опустив ее до субнанометрового уровня. Эффектив-

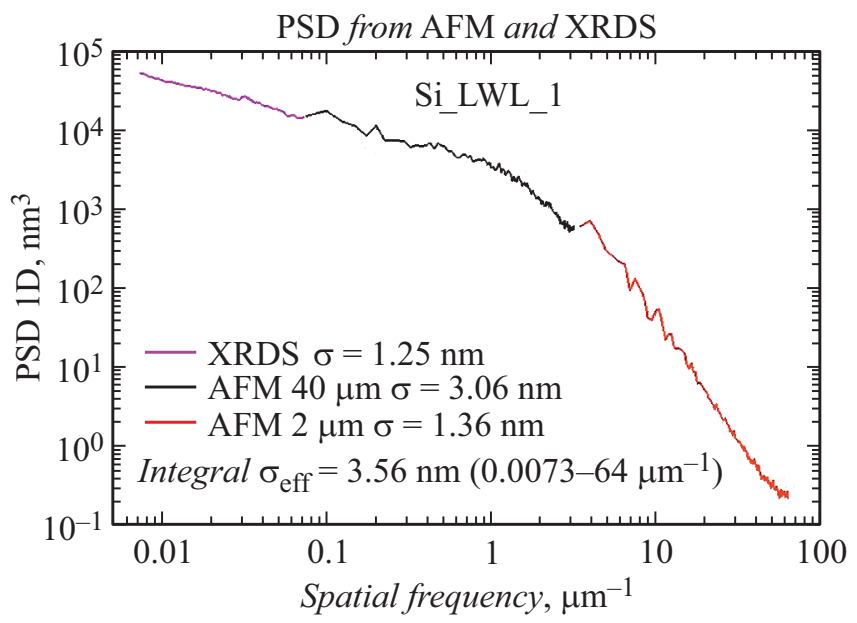

Рис. 8. PSD-функция шероховатости, построенная по данным АСМ и ДРРИ. 

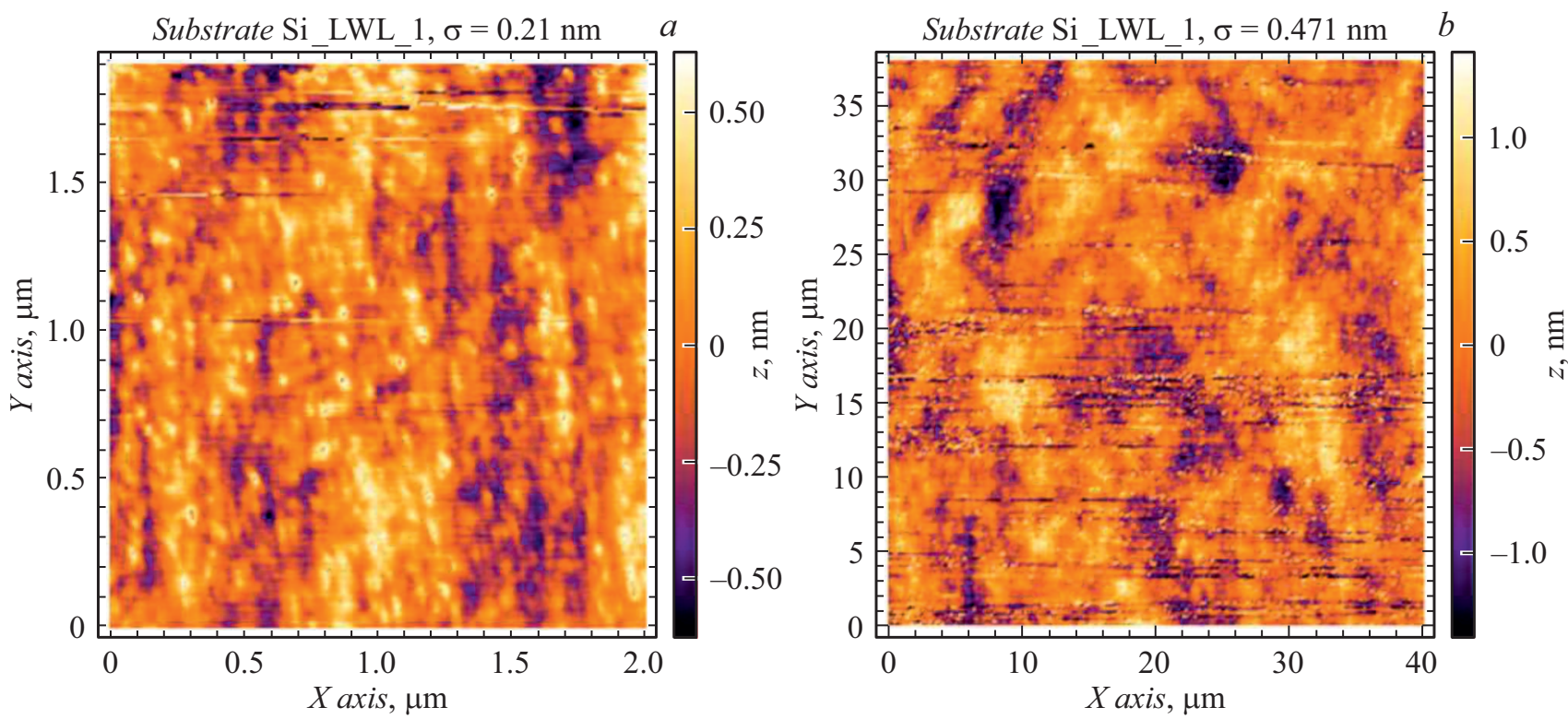

Рис. 9. АСМ изображения поверхности исследуемого образца после ГШП без ХМП и с доводкой нанопорошками СеО 2 .

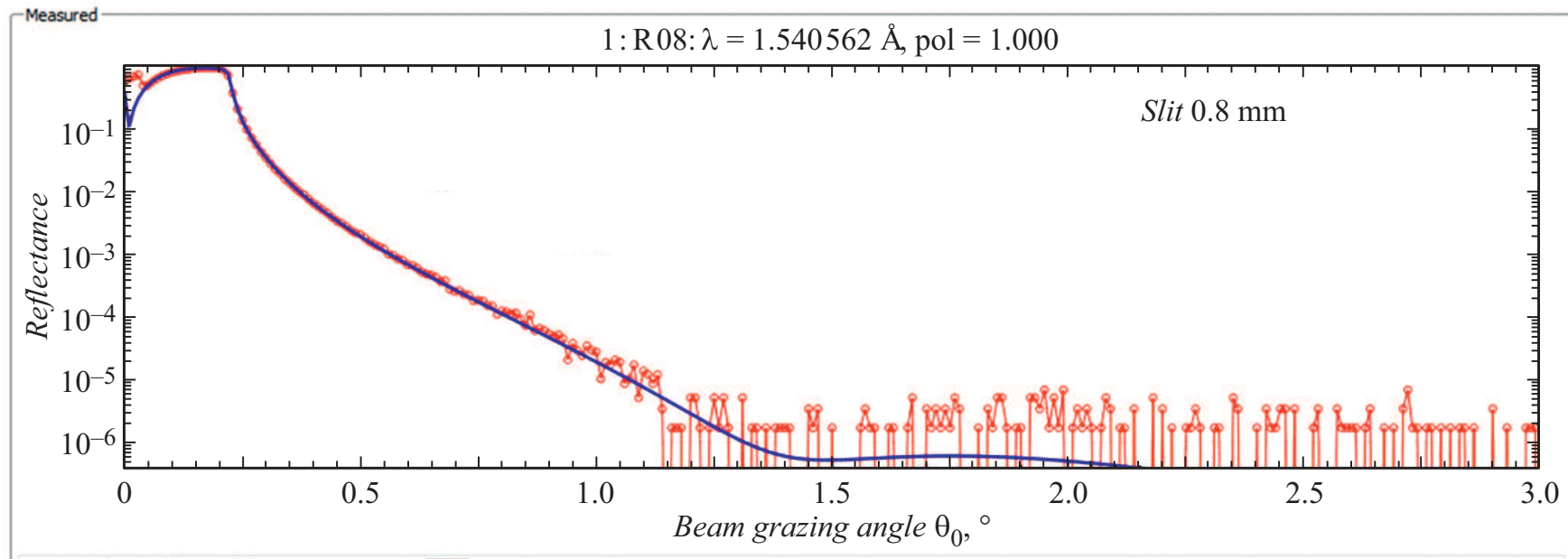

Scale Y: $\bigcirc$ Lin $\bigcirc$ Log $\square$ Rescale Log range: 6.4
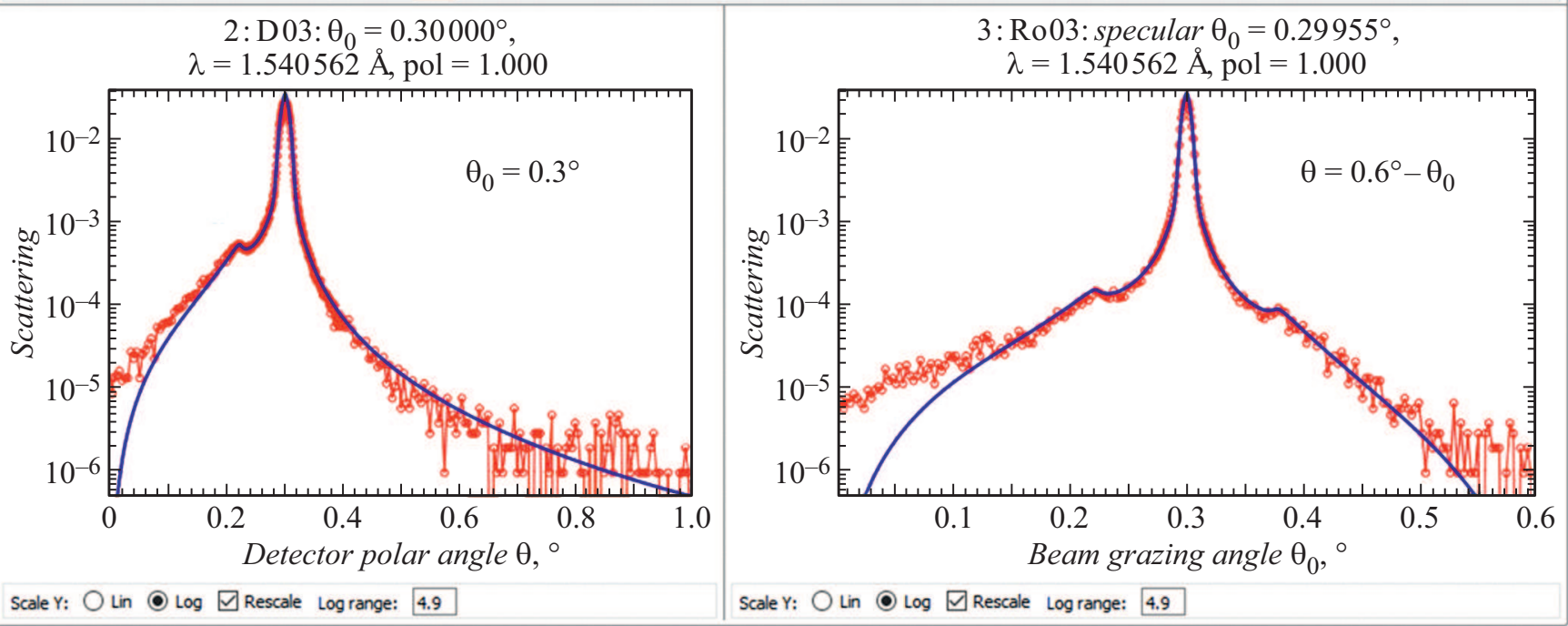

Scale Y: $\bigcirc$ Lin $\bigcirc$ Log $\square$ Rescale Log range: 4.9

Рис. 10. Кривые зеркального отражения (сверху), измеренные с различными щелями на детекторе, диффузного рассеяния (внизу) для исследуемого образца после ГШП без ХМП, но с доводкой нанопорошками $\mathrm{CeO}_{2}$. 


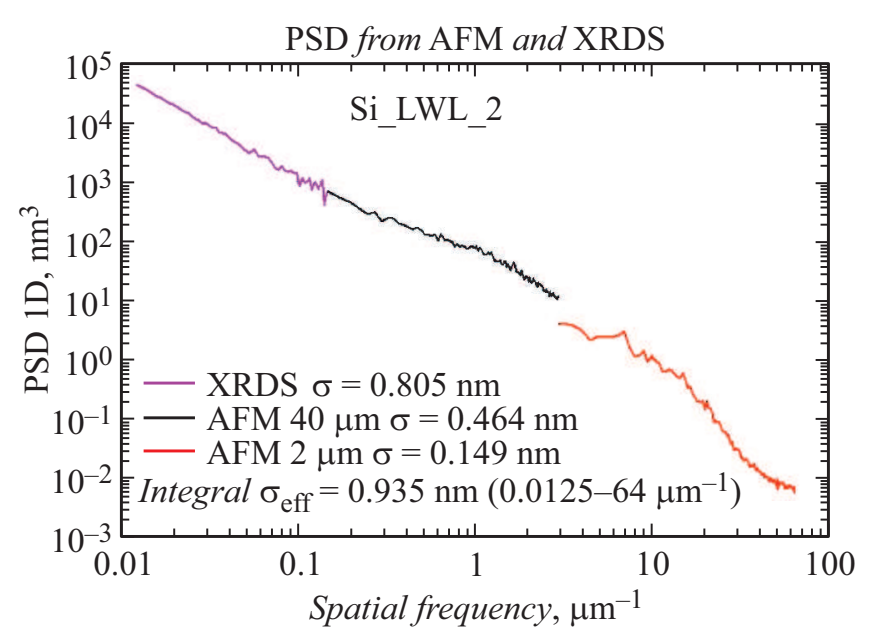

Рис. 11. PSD-функция шероховатости, построенная по данным АСМ и ДРРИ.

ная шероховатость в диапазоне частот $0.0125-64 \mu \mathrm{m}^{-1}$ составила около $0.93 \mathrm{~nm}$.

\section{3. Обсуждение результатов и основные выводы}

В настоящей работе проведено сравнение шероховатости поверхности подложек из монокристаллического кремния, подвергнутых стандартной ГШП с использованием абразивов на основе карбида бора, алмазных микропорошков и полирита, но с разной обработкой на финальной стадии. Первый способ, с использованием ХМП, как и ожидалось, позволяет получать подложки по шероховатости, удовлетворяющие требованиям к подложкам для рентгеновских зеркал. Главная проблема ХМП - практически невозможность получения высокоточных поверхностей, связанная с использованием „мягких“ полировальников и большой скорости травления.

Подложка, полученная методом ГШП без ХМП с использованием смоляных полировальников, показала высокий уровень шероховатости, на уровне $3.56 \mathrm{~nm}$ в диапазоне пространственных частот $0.0073-64 \mu \mathrm{m}^{-1}$, что исключает ее использование в рентгенооптике. Мы также сталкиваемся здесь с проблемой адекватного описания кривых отражения и ДРРИ в рамках теории возмущений по высоте шероховатостей по причине невыполнения условия (3) из-за большой шероховатости. Точное описание при любых параметрах падающего излучения и шероховатости возможно с использованием строгой электромагнитной теории [34-36].

Применение к этой подложке финальной доводки с использованием суспензии на основе нанопорошков оксида церия существенно улучшило качество поверхности. Эффективная шероховатость снизилась до $0.93 \mathrm{~nm}$. Для сравнения при ХМП шероховатость составила $0.54 \mathrm{~nm}$.

\section{Заключение}

Таким образом, показана принципиальная возможность получения кремниевых монокристаллических подложек методом механического притира без использования ХМП с субнанометровой шероховатостью, что уже близко к требованиям для рентгенооптических приложений. Дальнейшие шаги будут направлены на оптимизацию параметров технологического процесса: выбор марки смолы, температуры в процессе обработки, времени обработки, ионно-пучковая полировка с тем, чтобы достичь, или даже превзойти характеристики кремниевых подложек с ХМП.

\section{Благодарности}

Работа выполнена при поддержке РНФ, Соглашение № 21-72-20108.

\section{Конфликт интересов}

Авторы заявляют, что у них нет конфликта интересов.

\section{Список литературы}

[1] S.V. Rashchenko, M.A. Skamarokha, G.N. Baranov, Y.V. Zubavichus, Ia.V. Rakshun. AIP Conf. Proceed., 2299, 060001 (2020). DOI: org/10.1063/5.0030346

[2] G. Admans, P. Berkvens, A. Kaprolat, J.-L. Revol. ESRF upgrade programme phase II (2015-2022). Technical design study. (Imprimerie de Pont de Claix (C ESRF, 2014) p. 192. http://www.esrf.eu/Apache_files/Upgrade/ESRF-orange-book.pdf.

[3] Электронный ресурс. Режим доступа: https://www.maxiv.lu.se/about-us/

[4] A. Erko, M. Idir, Th. Krist, A.G. Michette. Modern Developments in $X$-ray and Neutron Optics (Springer Berlin Heidelberg, NY., 2008), p. 533. ISBN 978-3-540-74560-0

[5] Ch. Morawe, R. Barrett, K. Friedrich, R. Klünder, A. Vivo. J. Phys.: Conf. Series, 425, 052027 (2013). DOI: $10.1088 / 1742-6596 / 425 / 5 / 052027$

[6] S.S. Andreev, M.S. Bibishkin, N.I. Chkhalo, E.B. Kluenkov, K.A. Prokhorov, N.N. Salashchenko, M.V. Zorina, F. Schafers, L.A. Shmaenok. J. Synchrotron Radiation, 10 (5), 358 (2003). DOI: $10.1107 /$ S0909049503015255

[7] P.Z. Takacs. Synchrotron Radiation News, 2 (26), 24 (1989).

[8] Н.И. Чхало, М.В. Зорина, И.В. Малышев, А.Е. Пестов, В.Н. Полковников, Н.Н. Салащенко, Д.С. Казаков, А.В. Мильков, И.Л. Струля. ЖТФ, 89 (11), 1686 (2019). DOI: $10.21883 / J T F .2019 .11 .48329 .134-19$

[9] H. Thiess, H. Lasser, F.Siewert. Nucl. Instrum. Methods Phys. Res. A, 616, 157 (2010). DOI: 10.1016/j.nima.2009.10.077

[10] K.N. Khatri, R. Sharma, V. Mishra, H. Garg, V. Karar. Advan. Mater. Proceed., 2 (7), 425 (2017). DOI: $10.5185 / \mathrm{amp} .2017 / 704$

[11] L.N. Abdulkadir, K. Abou-El-Hossein, A.I. Jumare, P.B. Odedeyi, M.M. Liman, T.A. Ola niyan. Int. J. Adv. Manuf. Technol., 96, 173 (2018). DOI: 10.1007/s00170-017-1529-x

[12] T. Arnold, G. Bohm, R. Fechner, J. Meister, A. Nickel, F. Frost, T. Hansel, A. Schindler. Nucl. Instrum. Methods Phys. Res., A 616, 147 (2010). DOI: 10.1016/J.NIMA.2009.11.013 
[13] М.А. Окатов, Э.А. Антонов, А. Байгожин, М.И. Бакаев, И.В. Белова, И.Я. Бубис, В.А. Вейденбах, Н.М. Воронцова, С.В. Данилов, Н.Ю. Дудкина, И.И. Духопел, С.М. Кузнецов, 3.А. Куклева, Г.В. Листратова, Б.И. Лодыгин, Ю.К. Лысяный, С.В. Любарский, А.В. Михайлов, В.Я. Назарова, Е.И. Понфиленок, Б.И. Петров, Г.Т. Петровский, В.П. Повещенко, Г.Д. Придатко, С.М. Прохорчик, В.Н. Савушкин, Р.С. Соколова, Н.В. Суйковская, Л.В. Тарновская, И.Д. Торбин, Л.А. Черезова, Б.А. Чунин, А.В. Шатилов, Э.И. Шепурев, 3.В. Широкшина, В.Х. Ягмуров. Справочник технолога-оптика, под ред. М.А. Окатова. (Политехника, СПб, 2004), с. 679.

[14] U. Dinger, F. Eisert, H. Lasser, M. Mayer, A. Seifert, G. Seitz, S. Stacklies, F.-J. Stickel, M. Weiser. Proceed. SPIE, 4146, 35 (2000). DOI: 10.1117/12.406674

[15] K. Yamauchi, H. Memura, K. Inagaki, Y. Mori. Rev. Sci. Instrum., 73 (11), 4028 (2002). DOI: 10.1063/1.1510573

[16] Электронный ресурс. Режим доступа: https://www.j-tec.co.jp/english/optical/

[17] В.А. Смирнов. Обработка оптического стекла (Машиностроение, Л., 1980), с. 183.

[18] N.I. Chkhalo, I.A. Kaskov, I.V. Malyshev, M.S. Mikhaylenko, A.E. Pestov, V.N. Polkovnikov, N.N. Salashchenko, M.N. Toropov, I.G. Zabrodin. Precision Engineer., 48, 338 (2017).

DOI: http://dx.doi.org/10.1016/j.precisioneng.2017.01.004

[19] M.N. Brychikhin, N.I. Chkhalo, Ya.O. Eikhorn, I.V. Malyshev, A.E. Pestov, Yu.A. Plastinin, V.N. Polkovnikov, A.A. Rizvanov, N.N. Salashchenko, I.L. Strulya, M.N. Toropov. Appl. Optics, 55 (16), 4430 (2016). DOI: 10.1364/AO.55.004430

[20] N.I. Chkhalo, I.V. Malyshev, A.E. Pestov, V.N. Polkovnikov, N.N. Salashchenko, M.N. Toropov, S.N. Vdovichev, I.L. Strulya, Yu.A. Plastinin, A.A. Rizvanov. J. Astronom.Telescop., Instrum., Systems, 4(1), 0140031-014003-9 (2018). DOI: 10.1117/1.JATIS.4.1.014003

[21] N.I. Chkhalo, S.A. Churin, A.E. Pestov, N.N. Salashchenko, Yu.A. Vainer, M.V. Zorina. Opt. Express, 22 (17), 20094 (2014). DOI: 10.1364/OE.22.020094

[22] N.I. Chkhalo, S.A. Churin, M.S. Mikhaylenko, A.E. Pestov, V.N. Polkovnikov, N.N. Salashchenko, M.V. Zorina. Appl. Optics, 55 (6), 1249 (2016). DOI: 10.1364/AO.55.001249

[23] М.Н. Торопов, А.А. Ахсахалян, М.В. Зорина, Н.Н. Салащенко, Н.И. Чхало, Ю.М. Токунов. ЖТФ, 90 (11), 1958 (2020). DOI: 10.21883/JTF.2020.11.49990.127-20

[24] M.M. Barysheva, Yu.A. Vainer, B.A. Gribkov, M.V. Zorina, A.E. Pestov, D.N. Rogachev, N.N. Salashenko, N.I. Chkhalo. Bull. Russ. Academy Sci.: Physics, 75(1), 67 (2011). DOI: $10.3103 /$ S1062873811010059

[25] R. Blunt. Proceedings of CEMANTECH Conference (Vancouver, Canada, April 24-27, 2006), p. 59-62.

[26] D. Martinez-Galarce, R. Soufli, D.L. Windt, M. Bruner, E. Gullikson, Sh. Khatri, E. Spiller, J.C. Robinson, Sh. Baker, E. Prast. Opt. Engineer., 52 (9), 095102-1-14 (2013). DOI: 10.1117/1.OE.52.9.095102

[27] I.V. Kozhevnikov, M.V. Pyatakhin. J. X-ray Sci. Technol., 8 (4), 253 (1998).

[28] V.E. Asadchikov, I.V. Kozhevnikov, Yu.S. Krivonosov, R. Mercier, T.H. Metzger, C. Morawe, E. Ziegler. Nucl. Instrum. Meth. Phys. Res. A, 530, 575 (2004). DOI: 10.1016/J.NIMA.2004.04.216
[29] M.M. Barysheva, N.I. Chkhalo, M.N. Drozdov, M.S. Mikhailenko, A.E. Pestov, N.N. Salashchenko, Yu.A. Vainer, P.A. Yunin, M.V. Zorina. J. X-Ray Sci. Technol., 27 (5), 857 (2019). DOI: 10.3233/XST-190495

[30] J.E. Griffith, D.A. Grigg. J. Appl. Phys., 74 (9), 83 (1993). DOI: $10.1063 / 1.354175$

[31] N.I. Chkhalo, N.N. Salashchenko, M.V. Zorina. Rev. Sci. Instrum., 86, 016102 (2015). https://doi.org/10.1063/1.4905336

[32] M. Svechnikov. J. Appl. Crystall., 53(1), 244 (2020). DOI: $10.1107 / \mathrm{s} 160057671901584 \mathrm{x}$

[33] A.R. Belure, A.K. Biswas, D. Raghunathan, Rishipal, S. Bhartiya, R. Singh, S.K. Rai, R.S. Pawade, M.P. Kamath, N.S. Benerji., Mater. Today: Proceed., 26, 2260 (2020). DOI: $10.1016 /$ j.matpr.2020.02.490

[34] A.V. Andreev. Phys. Lett. A, 219 (5-6), 349 (1996). DOI: $10.1016 / 0375-9601(96) 00469-0$

[35] L.I. Goray. J. Appl. Phys., 108 (3), 033516 (2010). DOI: $10.1063 / 1.3467937$

[36] L. Goray. J. Synchrotron Radiat., 28 (1), 196 (2021). DOI: $10.1107 / \mathrm{S} 160057752001440 \mathrm{X}$ 